Originalveröffentlichung in: George-Jahrbuch 9 (2012/2013) (2012), S. 1-31

\author{
AufsäTZE
}

\title{
Michael Thimann
}

\section{Bildallegorien in der Buchgestaltung des George-Kreises}

Bekannt ist ein Ausspruch Stefan Georges, er habe nie eine Zeile geschrieben, die nicht erlebt war. ${ }^{1}$ In dieser Perspektive zerfällt sein lyrisches Werk auch nicht in einzelne Gedichte, sondern ist gewissermaßen als ein Ganzes zu verstehen, nämlich als die in der Lyrik aufgehobene Geschichte eines Ich. Dabei bleibt immer wieder zu diskutieren, inwiefern dieses Ich auch mit dem tatsächlichen Leben des Dichters Stefan George identisch ist. Es liegt auf der Hand, dass der Dichter Bilder finden muss, um über sein Ich zu sprechen. Diese können zunächst - auch wenn sie keine Realität abbilden - ganz im Gegenständlichen verbleiben. Hier genügt ein Verweis auf die typischen Bilder in Georges Frühwerk wie Park, Herbst, Spaziergang, italienische Landschaft usw. Was geschieht aber, wenn ein bildender Künstler Bilder zu der Dichtung entwirft, die nicht notwendig mit der Intention des Dichters übereinstimmen müssen? Dieses Problem, das traditionell als Dichtungsillustration bezeichnet wird, zutreffender aber wohl das "Zusammenspiel von Wort und Bild“ oder gar eine „Poetik synthetisierender Künste“ berührt, sei in das Zentrum dieses Beitrags gestellt. ${ }^{2}$ Dazu sei zu der eingangs zitierten Aussage Georges zurückgekehrt. Was heißt, George habe nicht eine Zeile geschrieben, die nicht erlebt gewesen sei, in Hinblick auf das Bild und auf die Möglichkeiten einer Illustration eben dieser Zeilen? Wird hier nicht bereits das Verbot der Übersetzung in ein anderes Medium (als Gebot der Unübersetzbarkeit) explizit gemacht? Ist mit der einmaligen medialen Transformation des Erlebten in das Sprachkunstwerk der Dichtung nicht bereits die Höchstform künstlerischer Gestaltung er-

1 Vgl. Claude David: Stefan George, München 1967, S. 106.

${ }^{2}$ Der Verfasser stellt das Thema der Buchillustration hiermit ganz bewusst in den größeren Zusammenhang einer Hermeneutik von Wort-Bild-Beziehungen, wie er auch von der Emblem- und Impresenforschung beschrieben wird. Vgl. Dieter Sulzer: Poetik synthetisierender Künste und Interpretationen der Emblematik. In: Herbert Anton/Arthur Henkel (Hg.): Geist und Zeichen. Festschrift für Arthur Henkel zu seinem sechzigsten Geburtstag, Heidelberg 1977, S. 401-426. 
reicht? Und ist, betrachtet man die Bildproduktion des George-Kreises, nicht der Widerspruch eklatant, der sich aus dem dichterischen Anspruch auf eine allegorie-ferne Verkörperung, auf Verleiblichung und Vergottung ergibt, die eben alles andere als ein $\alpha \lambda \lambda \mu \gamma o \varrho \varepsilon เ v$ sei, - ist nicht der Widerspruch eklatant, wenn man die Ubiquität allegorischer Konzepte in den Publikationen und handgemalten Bildallegorien des George-Kreises in Betracht zieht? Warum verlangte Georges Dichtung, zumindest in ihrer publizierten Form bis etwa 1907, überhaupt noch Bilder? Der beschriebene Widerspruch ist mit historischen und rein kunsthistorischen Argumenten nicht zu lösen, auch wenn er sich vor allem aus der letztlich wohl asymmetrischen Zusammenarbeit unterschiedlich ausgerichteter Künstlerpersönlichkeiten - Melchior Lechter und Stefan George - ergeben hat. Doch man würde es sich zu einfach machen, lediglich achselzuckend über die Reste einer gescheiterten künstlerischen Symbiose hinwegzugehen, in der Lechter zwangsläufig immer als der große Verlierer erscheinen muss.

\section{Lechter und George}

Verantwortlich für die eminente Rolle von Bildern und Allegorien in der Buchgestaltung des George-Kreises ist bekanntlich die um 1895 erfolgte Hinzuziehung des Illustrators und Glasmalers Melchior Lechter durch George, der mit einer bemerkenswerten Duldung durch den Dichter, ja einer großen gestalterischen Freiheit die Bildwelt des George-Kreises, zumindest in den Publikationen bis etwa 1907, entworfen hat. Die Verwendung stilisierter Bilder und Ornamente als progressive Buchgestaltung war zunächst eine Kampfansage gegen den Naturalismus und die billige Druckindustrie, die das ,schöne Buch' in der zweiten Hälfte des 19. Jahrhunderts zu einem geschmacklos gestalteten Massenartikel degradiert hatte. Man kann für den Zeitraum von 1897 bis 1907 davon ausgehen, dass George selbst die aufwendige Gestaltung der Publikationen in Richtung des buchkünstlerischen Gesamtkunstwerks, für die ausschließlich Lechter verantwortlich zeichnet, ideell getragen hat. ${ }^{3}$ Bei der Einkleidung der Gedichte in ein gotisches Gewand ließ er Lechter erstaunliche Freiheit. Lechters Vorliebe für William Morris und die

${ }^{3}$ Die intensive Zusammenarbeit dokumentiert der Briefwechsel: Melchior Lechter und Stefan George. Briefe. Kritische Ausgabe. Hg. von Günter Heintz, Stuttgart 1991. 
Kelmscott-Press, seine Sensibilität für die ästhetischen Reize der Formenwelt des gotischen Mittelalters, die Gestaltung von Handschriften und Frühdrucken, sein Hang zum nazarenisch inspirierten Mystizismus und zur Romantik ${ }^{4}$ sowie sein großes technisches Können und Selbstverständnis als Meister einer mit höchsten Ansprüchen arbeitenden Handwerkskunst haben die Publikationen vom ,Jahr der Seele' bis zum ,Siebenten Ring' zu herausragenden Werken der Buchkunst in Deutschland um 1900 gemacht. In ihrem progressiven Anspruch, für Deutschland den Anschluss an die internationale Formensprache der Art nouveau und Stilkunst zu leisten, können sie den Arbeiten Henry van de Veldes, den Publikationen der ,Insel` und des Verlags Eugen Diederichs an die Seite gestellt werden. ${ }^{5}$

Gleichwohl barg Lechters Projekt einer Bergung der Georgeschen Poesie in einer kostbaren ,Buch-Kathedrale ${ }^{6}$, wie sie wohl vor allem der ,Teppich des Lebens‘ (1899/1900) mit seinem Rahmenwerk von sakraler Symbolik darstellt, auch Probleme. Georges Interesse an aufwendig gestalteten Büchern, die den Text der Dichtung in Bild- und Rahmenwerk einer dekadenten Phantasie-Gotik einbetten, sank nach 1900, so dass er schon mit ,Tage und Taten' von 1903 zu den Prinzipien äußerst schlichter, allein auf der Wirkung der seriphenlosen Typen beruhenden Gestaltung zurückkehrte, welche schon die ersten Gedichtbände ausge-

${ }^{4}$ Verf.: Geheiligte Überlieferung. Melchior Lechter und die deutsche Kunst am Ende des 19. Jahrhunderts. In: Jürgen Krause/Sebastian Schütze (Hg.): Melchior Lechters Gegen-Welten. Kunst um 1900 zwischen Münster, Indien und Berlin. Ausstellungskatalog, Münster, Westfälisches Landesmuseum für Kunst und Kulturgeschichte, Berlin - Münster 2006, S. 55-63.

${ }^{5}$ Zur Bedeutung der Buchkunst Lechters vgl. Wolfhard Raub: Melchior Lechter als Buchkünstler. Darstellung, Werkverzeichnis, Bibliographie, Köln 1969; Bert Treffers: Melchior Lechters Buchkunst. In: Melchior Lechter. Der Meister des Buches. 1865-1937. Eine Kunst für und wider Stefan George, Amsterdam 1987 (Castrum Peregrini, 179-180), S. 5-19; Karlhans Kluncker: Dichtung und Buchschmuck. Melchior Lechter zum 50. Todestag. In: Ebd., S. 20-60; Sebastian Schütze: Ein Gotiker im George-Kreis. Melchior Lechter und die Erneuerung der Kunst aus dem Geist des Mittelalters. In: Barbara Schlieben/Olaf Schneider/Kerstin Schulmeyer (Hg.): Geschichtsbilder im George-Kreis. Wege zur Wissenschaft, Göttingen 2004, S. 147-182; Wolfhard Raub: Melchior Lechter als Buchkünstler. In: Krause/Schütze, Melchior Lechters Gegen-Welten (Anm. 4), S. 129-145; Ute Oelmann: Vom handgeschriebenen Buch zur Erstausgabe. Schrift- und Buchkunst Stefan Georges. In: Castrum Peregrini 56, 2007, H. 276-277, S. 63-76. 
zeichnet hatte. Hier ist das von Stefan George wohl weitgehend selbst entworfene Titelblatt der ,Hymnen' von 1890 zu nennen. Die Lechters ,Buch-Kathedrale' kennzeichnenden ikonographischen Motivschleifen von Engeln, Weihrauch, Wolken, gotischen Monstranzen, Brunnen, Leuchtern, Sternen, Altären, Kelchen, Kreuzen und Harfen dienten der Auratisierung des Buchobjekts, indem ihm der Charakter des Sakralen verliehen wurde, was wiederum mit der quasi rituellen Verwendung der Objekte in der Lesung und ihrer absichtsvollen Exklusivität zu begründen ist. Die Buchgestaltung ist voll von religiösen Verweisen christlicher Provenienz. Doch verweisen diese nicht auf Theologeme des christlichen Glaubens, sondern eher auf sich selbst, auf die dezidiert religiöse Auffassung von der Kunst.

Neben dem gotischen Rahmenwerk gibt es Bildallegorien. Deren Darstellungen sind einerseits von den Gedichten inspiriert, andererseits stehen sie in älterer Tradition vor allem mittelalterlicher und frühneuzeitlicher Buchproduktion. Einige dieser Bildallegorien aus dem Kreis der ,Blätter für die Kunst' seien im Folgenden auf ihre motivischen und bildhistorischen Kontexte hin befragt. Zunächst ist zu differenzieren zwischen dem Gebrauch allegorischer Bildgegenstände und demjenigen symbolistischer Bilder, wie sie etwa in den Bildbeigaben der,Blätter für die Kunst' $\mathrm{zu}$ finden sind. So ist Fernand Khnopffs ,Une ville morte ${ }^{6}$ von 1889 (Abb. 1), deren Reproduktion dem 3. Band der 2. Folge von 1894 beigegeben war, ${ }^{6}$ in ihrem direkten Bezug auf Georges Rodenbachs ,Bruges la morte ${ }^{6}$ ein typisches Zeugnis des französisch-belgischen Symbolismus - ein dekadentes Stimmungsbild von Tod und $\mathrm{Zu}$ spät-Geborensein, eine rêverie über Macht, Schönheit und Verfall, aber eben kein begrifflich auflösbarer Verweis auf ein Abstraktum, wie er für die Allegorie in Anspruch genommen werden kann. In Lechters Buchkunst sind die symbolistischen Quellen und Bezüge offenkundig, doch findet er zu einer verfestigten Bildsprache, in der die bildlichen Informationen semantisch klarer kodiert werden. Allein die Wiederverwen-

${ }^{6}$ Der Belgier Paul Gérardy hatte Khnopff veranlasst, das im Juni 1894 auf der Münchner Sezessionsausstellung gezeigte Gemälde, dessen morbide Stimmung den frühen Gedichten Georges, Gérardys, Andrians und Wolfskehls nahesteht, in den ,Blättern für die Kunst' reproduzieren zu lassen, vgl. Karlhans Kluncker: Blätter für die Kunst. Zeitschrift der Dichterschule Stefan Georges, Frankfurt a.M. 1974 (Studien zur Philosophie und Literatur des neunzehnten Jahrhunderts 24), S. 70-71. 
dung der gotisch-sakralen Motive wie Altar, Kelch und Engel macht deutlich, dass es ihm nicht um Stimmung allein, sondern um eine ikonographisch entschlüsselbare Bildsprache ging. Schon Wolfhard Raub formulierte 1969 ganz zutreffend: „Lechters Buchkunst ist also, soweit sie nicht rein dekorativ ist, weithin Ideenkunst. Das Bild ist nie ohne Symbolwert und will den Empfänglichen einführen in das verborgene Wesen des Textes oder auf seinen Ursprung deuten. Niemals aber will

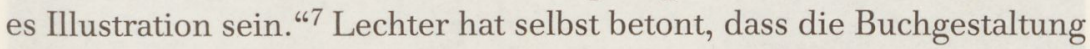
nicht illustriere, sondern immer etwas eigenes darstelle, was freilich den Text (gerade im Falle Stefan Georges) nicht verdecken darf. Vielmehr solle die unsichtbare Seele der Verse oder Prosa den Leser wie stumme Musik umfangen, und dazu dient auch die Stiftung von Evidenz durch das Bild. Dieses Konzept hat die Bilderwelt des George-Kreises entscheidend geprägt. Eröffnet wird dies programmatisch durch den Engel auf dem Titel des ,Jahrs der Seele von 1897 (Abb. 2), der ein programmatischer Rückgriff auf die Buchgestaltung des Spätmittelalters in gotischen Formen und die Ästhetik des Holzschnitts ist. Dabei handelt es sich technisch gar nicht um einen Holzschnitt, sondern um eine reproduzierte Zeichnung. Das Mittelalter ist hier eine Geste, das sakrale Motiv des orgelspielenden Engels verweist auf den himmlischen Ursprung der Dichtung als einer Sprache der Engel. Doch ist der Engel im Kontext dieses profanen Stundenbuches ein Genius der Kunst und damit seiner sakralen Funktion gleichsam wieder enthoben.

\section{Epiphanie}

Einen Riss bekam die Zusammenarbeit mit Lechter bekanntlich schon 1905/06 anlässlich der Produktion des Gedenkbuches für Maximin (Abb. 3). ${ }^{8}$ Hier lässt sich ein Bruch mit der Allegorie beschreiben, der Einbruch des Realen in die Welt der Kunst durch die Einfügung des fotografischen Portraits von Maximilian Kronberger in die Titelgestaltung des Gedenkbuches, das Lechter nur durch einen ornamentalen Rahmen

\footnotetext{
${ }^{7}$ Vgl. Raub, Melchior Lechter als Buchkünstler (Anm. 5), S. 30.

${ }^{8}$ Maximin. Ein Gedenkbuch. Hg. von Stefan George, Berlin 1906. Zur Symbolik des Buchschmuckes vgl. Martin Roos: Stefan Georges Rhetorik der Selbstinszenierung, Düsseldorf 2002, S. 86-99; Jan Stottmeister: Pythagoreische Elemente in Stefan Georges Maximin-Kult. In: George-Jahrbuch 6, 2006/2007, S. $122-149$.
} 


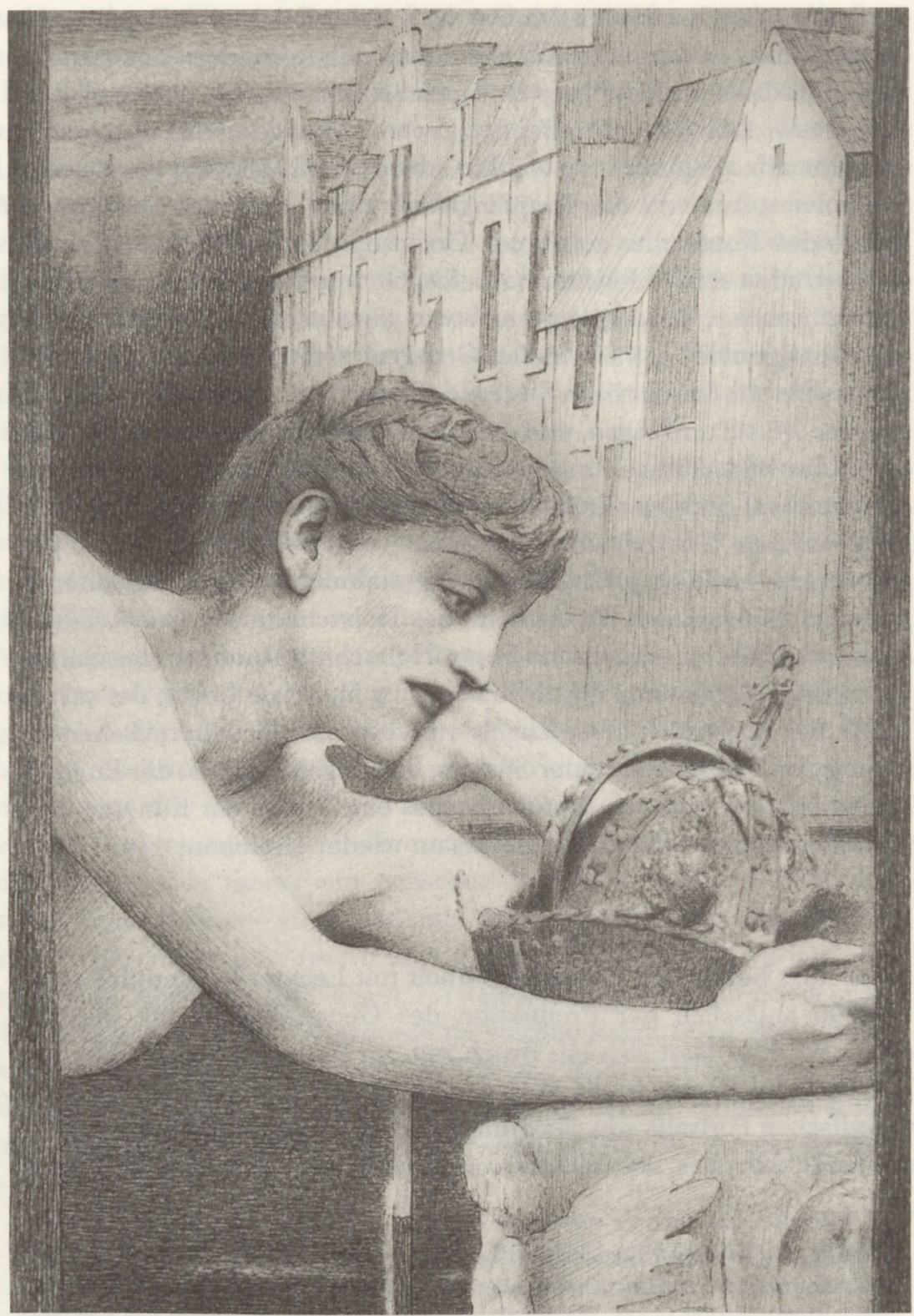

Abb. 1 Fernand Khnopff: ,Une ville morte (Avec Georges Rodenbach)', 1889, London, Privatbesitz (Bildvorlage hier und in allen weiteren Fällen des Beitrags: Michael Thimann) 


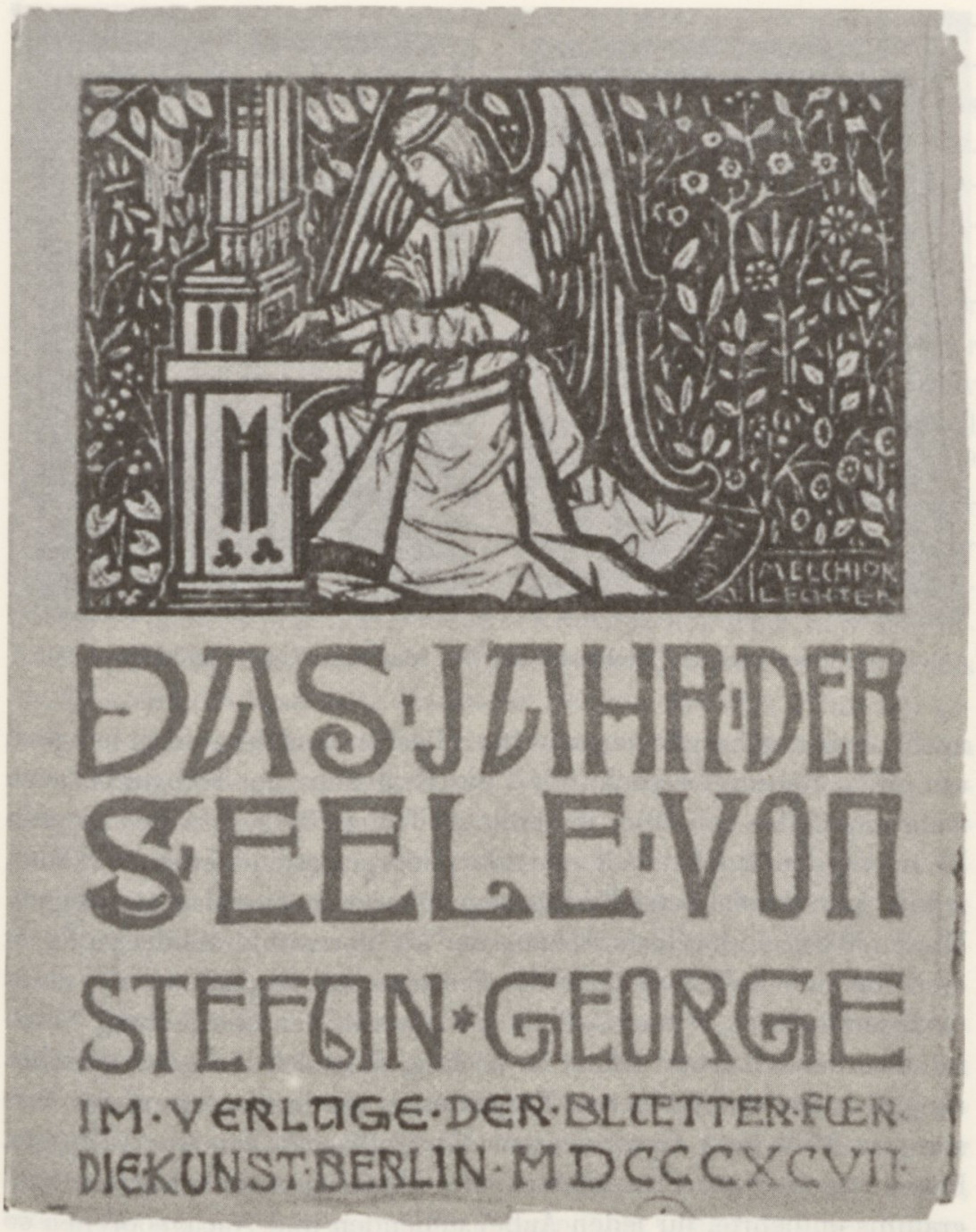

Abb. 2 Melchior Lechter, Titelblatt für das ,Jahr der Seele', 1897 


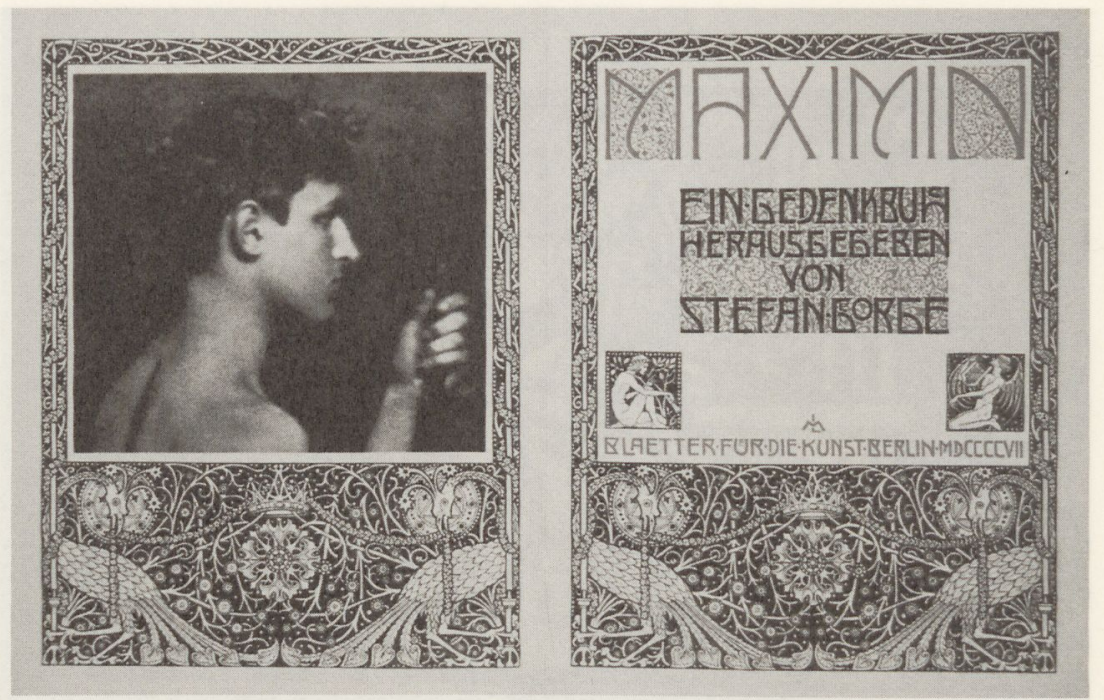

Abb. 3 Melchior Lechter, Titelgestaltung für,Maximin. Ein Gedenkbuch‘, 1906

noch kostbar zu bergen versucht hat. Hierbei handelte es sich lediglich um einen Rettungsversuch, denn der Realismus der Fotografie, auch wenn zweifellos von einer inszenierten Fotografie gesprochen werden kann, war dem Buchkünstler zuwider. George bestand darauf, ein Foto, jedoch kein gezeichnetes Bildnis gegenüber dem Titelblatt einzufügen. Diesen Wechsel der Technik hatte der Dichter wohldurchdacht: Es ist eine mediale Reflexion über die Präsenzerfahrung Maximins, eines Gotteserlebnisses, wie es sich für George mit der Erscheinung Maximins verbunden hatte. Dabei ist wichtig, dass sich diese Gotteserfahrung nicht im Visionären und Körperlosen, sondern an der realen Person des Münchner Gymnasiasten Maximilian Kronberger vollzogen hatte, was Georges Privatmythos, der überdies eines religiösen Programms entbehrte, für jeden Außenstehenden und Nachgeborenen so schwer nachvollziehbar werden ließ. Natürlich handelt es sich bei dem Gedenkbuch um ein Werk gegen den Geschmack der großen Masse, die das übersinnliche Ereignis nicht nachvollziehen könne, wie George gegenüber Lechter betont hat. Doch die Einfügung der Fotografie trug dem Rang des Erlebnisses Rechnung, das den Bereich der Kunst überschritten hatte und für den Dichter eine andere Realität präsent werden ließ. Ein kunstloses Bild, als das die Fotografie hier beschrieben werden 
kann, signalisiert, dass die Sphäre der Kunst verlassen ist und das Maximin-Erlebnis das Leben angeht. Lechter hat das Foto künstlerisch nachbearbeitet, indem er eine Zinkätzung mit malerischen Valeurs daraus gemacht und ihm eine reich ziseliert wirkende Rahmung verliehen hat. Der sonstige Schmuck ist eher zurückhaltend, aber auch von ikonographischer Relevanz, da sich in ihm wieder Christliches mit Antikem vermischt. Die Pfauen beispielsweise sind altchristliche Unsterblichkeitssymbole, da ihr Fleisch angeblich nicht verwese. Sie sind also nicht nur Ausdruck von Erlesenem und Kostbarem, sondern Bedeutungsträger im Kontext des Totengedenkens. Diesem lässt sich auch das Motiv des Sterns zuweisen, für den Raub gezeigt hat, dass sich Lechter wohl motivisch an Ernst Haeckels ,Kunstformen der Natur' angelehnt hat. ${ }^{9}$ Die Verwandlung in einen Stern ist die antike bildliche Vorstellung für die Vergöttlichung, die Apotheose. Es wäre lohnend, die Bildwelt der George'schen Buchgestaltung einmal nach derartigen kosmischen Allegorien zu untersuchen. Die Evidenz des Kosmischen wird im MaximinKult augenfällig, denn mit dem von George proklamierten Auftreten des Gottes sollte die kosmische Harmonie, welche der Welt abhanden gekommen war, gewissermaßen wieder hergestellt worden sein. Doch sind Himmelsallegorien und astrale Themen in Anlehnung an Kosmosdiagramme und religiöse Bildallegorien älteren Typs in unterschiedlichen Zusammenhängen nachweisbar. Bei Lechter findet sich dabei Figürliches und Diagrammatisches nebeneinander, auch die ausgeprägte Zahlensymbolik - etwa die Siebenzahl, die sich namentlich im Buchschmuck des ,Siebenten Ringes' von 1907 zeigt - gehört in diesen Kontext. ${ }^{10}$ Auch Friedrich Gundolf, dessen Bildsprache als Zeichner hinsichtlich ihrer Stilisierung zweifellos von Lechter beeinflusst wurde, hat sich mit Kosmosallegorien beschäftigt. Eine auf 1902 datierbare Zeichnung (Abb. 4) auf dem Einband einer barocken Ausgabe aus seiner Caesar-Sammlung zeigt ein Kosmosmodell, um das ein Komet kreist, womit die schon von Ovid erzählte Verwandlung Caesars in einen Kometen nach seiner Ermordung visuell evident gemacht wird. ${ }^{11}$ Die Zeich-

${ }^{9}$ Raub, Melchior Lechter als Buchkünstler (Anm. 5), S. 135.

${ }^{10} \mathrm{Vgl}$. Stottmeister, Pythagoreische Elemente (Anm. 8), S. 132.

${ }^{11}$ Das Buch in Durham, Duke University Libraries, Kempner-Gundolf-Collection of Julius Caesar (Sign. E 12 mo \#5202 c.1), vgl. Verf.: Caesars Schatten. Die Bibliothek von Friedrich Gundolf. Rekonstruktion und Wissenschaftsgeschichte, Heidelberg 2003, S. 112-113. 


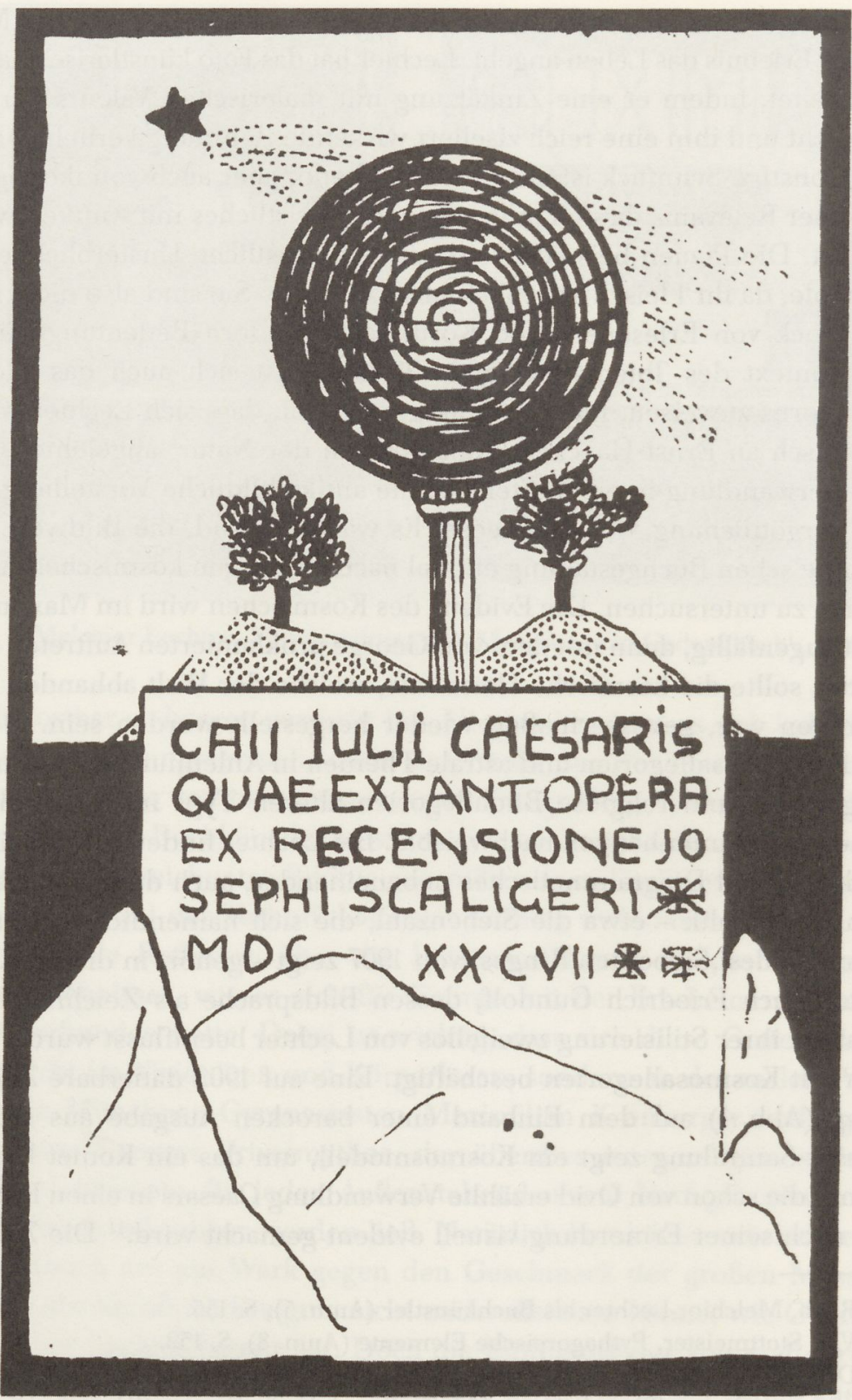

Abb. 4 Friedrich Gundolf, ,Caesar als Komet', Zeichnung auf dem Einband einer barocken Caesaredition, 1902, Durham, Duke University Libraries 
nung verbildlicht einerseits die mythische Verwandlung Caesars in einen Meteor, andererseits aber auch die Präsenz des antiken Weltenherrschers, indem sie den kosmischen Flug des ,julischen Kometen“ zeigt, den Gundolf etwa zeitgleich in einem Widmungsgedicht an Wolfskehl eng mit seiner eigenen Existenz, nämlich der Beendigung der Dissertation über das Nachleben Julius Caesars in der deutschen Literatur, verknüpft hatte: „Ich bleibe jetzt bescheidner wart / In unsren heimischen Blumenbeeten. / Zu lange hab ich nachgestarrt / Dem Flug des julischen kometen. "12 Die Repräsentation von Welt erfolgt in der Zeichnung im Bild eines Modells, nämlich einer vor einem Landschaftshintergrund platzierten Armillarsphäre, wie sie sich als Handgerät in Spätmittelalter und Früher Neuzeit nachweisen lässt. Ohne Zweifel ruft Gundolfs Zeichnung diese bildlichen Kontexte auf und beweist damit, bei allen eingestandenen technischen Schwierigkeiten in der zeichnerischen Bewältigung, eine Sensibilität für allegorische Bildprägungen.

\section{Wie Orpheus}

Wenn man so will, trat auch George selbst bildlich zunächst als Allegorie, nämlich als Personifikation einer mythologischen Figur, in Erscheinung. Schon 1896 stattete Lechter in dem Gemälde des ,Orpheus‘ (Abb. 5) den mythischen Sänger als Kryptoportrait mit den Zügen Georges aus. ${ }^{13}$ Im Anschluss an die ältere Forschung ist hier ein mythologisches Rollenportrait Georges zu erkennen, wogegen der jüngste Vorschlag, demzufolge dem Orpheus die Züge einer Frau eingeschrieben sein sollen,

${ }^{12}$ Friedrich Gundolf: Zwiegespräche, Berlin 1905, S. 41.

${ }^{13}$ Gemälde vorhanden in: Münster, Westfälisches Landesmuseum, Inv. Nr. 705 LG. Zum Gemälde vgl. Theodor Riewerts: Melchior Lechters ,Orpheus“. In: Westfalen 21, 1936, S. 157-159. Zur Ikonographie des mythischen Sängers s. zuletzt Volker Scherliess: Aspekte des Orpheus-Mythos. In: Wilfried Seipel (Hg.): Dipingere la musica. Musik in der Malerei des 16. und 17. Jahrhunderts, Mailand 2001, S. 55-59; Blick auf Orpheus. 2500 Jahre europäischer Rezeptionsgeschichte eines antiken Mythos. Hg. von Christine Mundt-Espín, Tübingen 2003 (Mainzer Forschungen zu Drama und Theater 29); Eva-Bettina Krems: Das Drama des Sehens und der Musik. Zur Darstellung des OrpheusMythos in bildender Kunst und Oper der Frühen Neuzeit. In: Marburger Jahrbuch für Kunstwissenschaft 36, 2009, S. 269-300. 


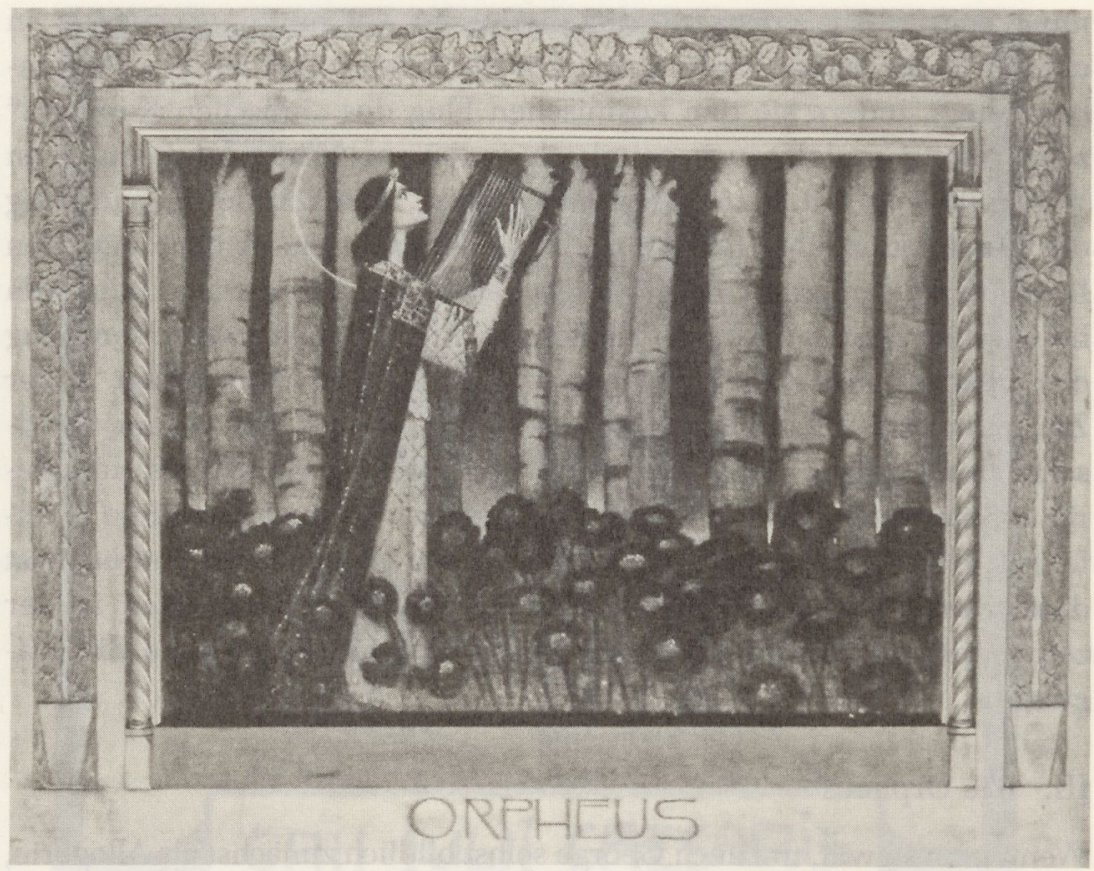

Abb. 5 Melchior Lechter, ,Orpheus‘, 1896, Münster, Westfälisches Landesmuseum

wenig überzeugend ist. ${ }^{14}$ Schon Karlhans Kluncker erkannte in der Bildgestalt eine „Stilisierung, der Georges Profil zugrunde liegt" ${ }^{15}$ Orpheus erscheint hier in ikonographischer Tradition, die gerade im Symbolismus, etwa bei Gustave Moreau, wieder als Bildgegenstand attraktiv wurde, als inspirierter Dichter und Priesterkönig; sein Blick ist nach oben gewandt, seine Hand greift in die Leier. Wie die Figur des Orpheus mit Aureole, Diadem und Sternenmantel ist auch die Bildform stilisiert, die Bäume bilden ein symmetrisches Ornament, in dem die Figur des Sängers geradezu versinkt. Die Blumen wenden ihre Köpfe dem Sänger zu. In diesem Gemälde und dem dazugehörigen Pastell probiert Lechter die Möglichkeiten des mythologischen Rollenportraits

14 Sonja Schön-Beetz: Melchior Lechter und seine Musen - „Der liebe fleisch und blut im sakrament". In: Krause/Schütze, Melchior Lechters Gegen-Welten (Anm. 4), S. 260.

15 Kluncker, Dichtung und Buchschmuck (Anm. 5), S. 32. 
aus. Orpheus ist der mythische Sänger, dessen schöne Lyrik Tiere und Pflanzen, ja selbst die ganze Unterwelt zum Weinen bringt. Georges Züge sind einer mythologischen Historie eingefügt, er erscheint auch hier als ein anderer, indem er zum mythischen Urbild aller Sänger, aber nicht zum Zeitgenossen der Gegenwart gemacht wird. Mit Hilfe bildlicher Stilisierung hat Lechter gleichsam behauptet, dass Georges Dichtertum ein überzeitlicher Rang zugesprochen werden kann.

\section{Allegorie und Bildnis}

Teil einer ungleich komplexeren allegorischen Bildhandlung wird George im Bildprogramm des Pallenbergsaals, den Lechter zwischen 1897 und 1903 im Kunstgewerbemuseum der Stadt Köln gestaltete, und der im Zweiten Weltkrieg vollständig zerstört wurde. Es handelte sich um ein die Architektur mit den verschiedensten Bildmedien (Plastik, Wand- und Glasmalerei, Intarsien) und kostbarsten Materialien verbindendes Gesamtkunstwerk, dessen Ikonographie und Inschriften einen zentralen Gedanken zum Ausdruck brachten: Die sakral aufgeladene Verehrung von Kunst und Künstlertum als einer säkularen Heilslehre, für die sich Lechter an unterschiedlichen Quellen, allen voran Richard Wagner, Nietzsche und George, inspiriert hatte. ${ }^{16}$ Das ornamentale Rahmenwerk war dabei integraler Bestandteil der Konzeption, indem es den untrennbaren Zusammenhang der Künste anschaulich machte. Das zentrale Wandbild zeigte die, Weihe am mystischen Quell' (Abb. 6). Im Sinne eines Initiationsritus tränkte eine Priesterin der im Heiligtum der Kunst entspringenden Quelle einen knienden Dichter, der eindeutig mit dem Profil Georges ausgestattet war, mit geweihtem Wasser. Alten Vorstellungen des furor poeticus folgend betonte die Inschrift das Rauschhafte der Inspiration, wie es Lechter durch die Apodiktik des Dionysischen bei Nietzsche vermittelt bekommen hatte: „Berufen durch des mystischen Quelles Trank empfange den heiligen Rausch aus dem geboren geweihte Werke." Georges Portrait war zwar deutlich identifizierbar - und es wurde als solches auch von den Zeitgenossen er-

${ }^{16}$ Zum Pallenberg-Saal vgl. Maximilian Rapsilber: Melchior Lechter, Berlin 1904, S. 77; Jürgen Krause: Melchior Lechters Pallenberg-Saal für das Kölner Kunstgewerbemuseum - Ein Kultraum der Jahrhundertwende im Zeichen Nietzsches und Georges. In: Wallraf-Richartz-Jahrbuch 45, 1984, S. 203-230; Krause/Schütze, Melchior Lechters Gegen-Welten (Anm. 4) (mit älterer Literatur). 


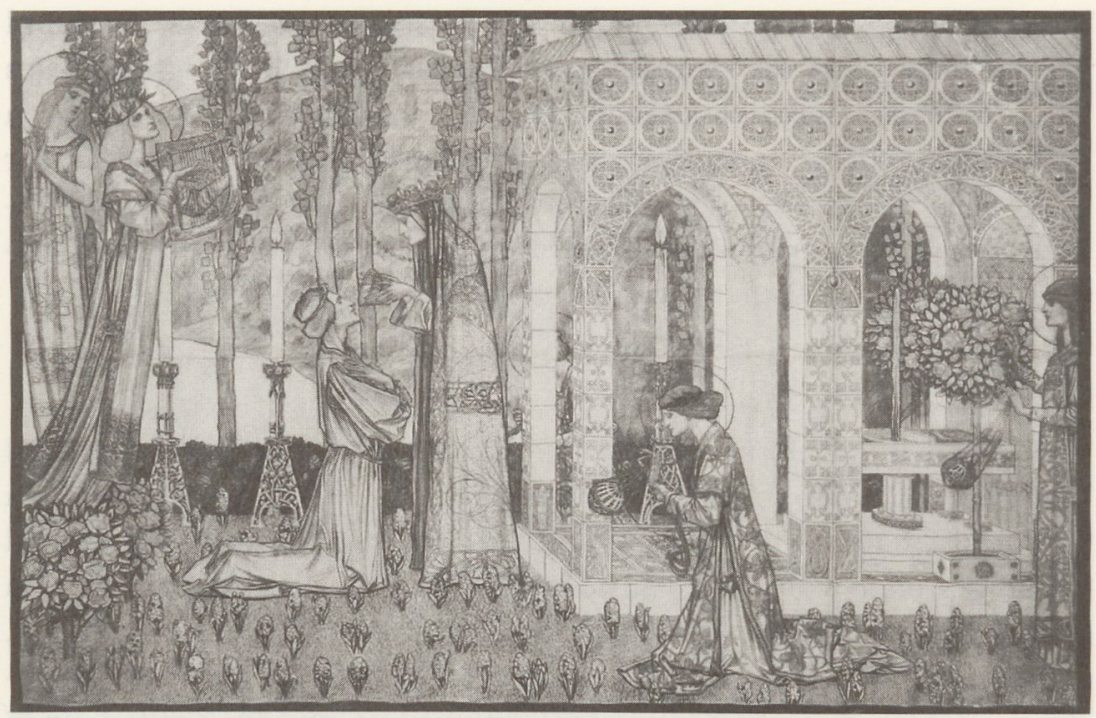

Abb. 6 Melchior Lechter, Entwurf für die ,Weihe am mystischen Quell', um 1898, Münster, Westfälisches Landesmuseum

kannt -, doch wurde seine Bedeutung als Erneuerer der deutschsprachigen Poesie und Überwinder des Naturalismus ins Allgemeine erhoben: George war die Personifikation des Künstlertums, das im rauschenden Schönheits- und Materialkult des Lechter'schen Jugendstils als ein Zusammenklang aller Künste aufging. Lechter erblickte im Zusammenspiel aller Künste (Bildkünste, Architektur, Musik und Poesie) die Verwirklichung eines Gesamtkunstwerks. In diesem Sinn wurde nicht George als Individuum verherrlicht, sondern als Prototyp des inspirierten Künstlers, dessen Inspiration wiederum mystisch ist, da sie über die Einnahme des geweihten Tranks vom mystischen Quell erfolgt. Erst im Kontext der Gesamtausgabe wurde das Bild wieder zum Portrait, da dem ,Teppich des Lebens' (1932) die als Vorstudie entstandene Kohlezeichnung vom 25. Oktober 1900 vorangestellt ist, womit die Signifikation gleichsam wieder eindeutig gemacht wurde. ${ }^{17}$

${ }^{17}$ Stefan George: Gesamt-Ausgabe der Werke. Endgültige Fassung. Bd. 5: Der Teppich des Lebens und die Lieder von Traum und Tod. Mit einem Vorspiel, Berlin 1927ff., Frontispiz. 


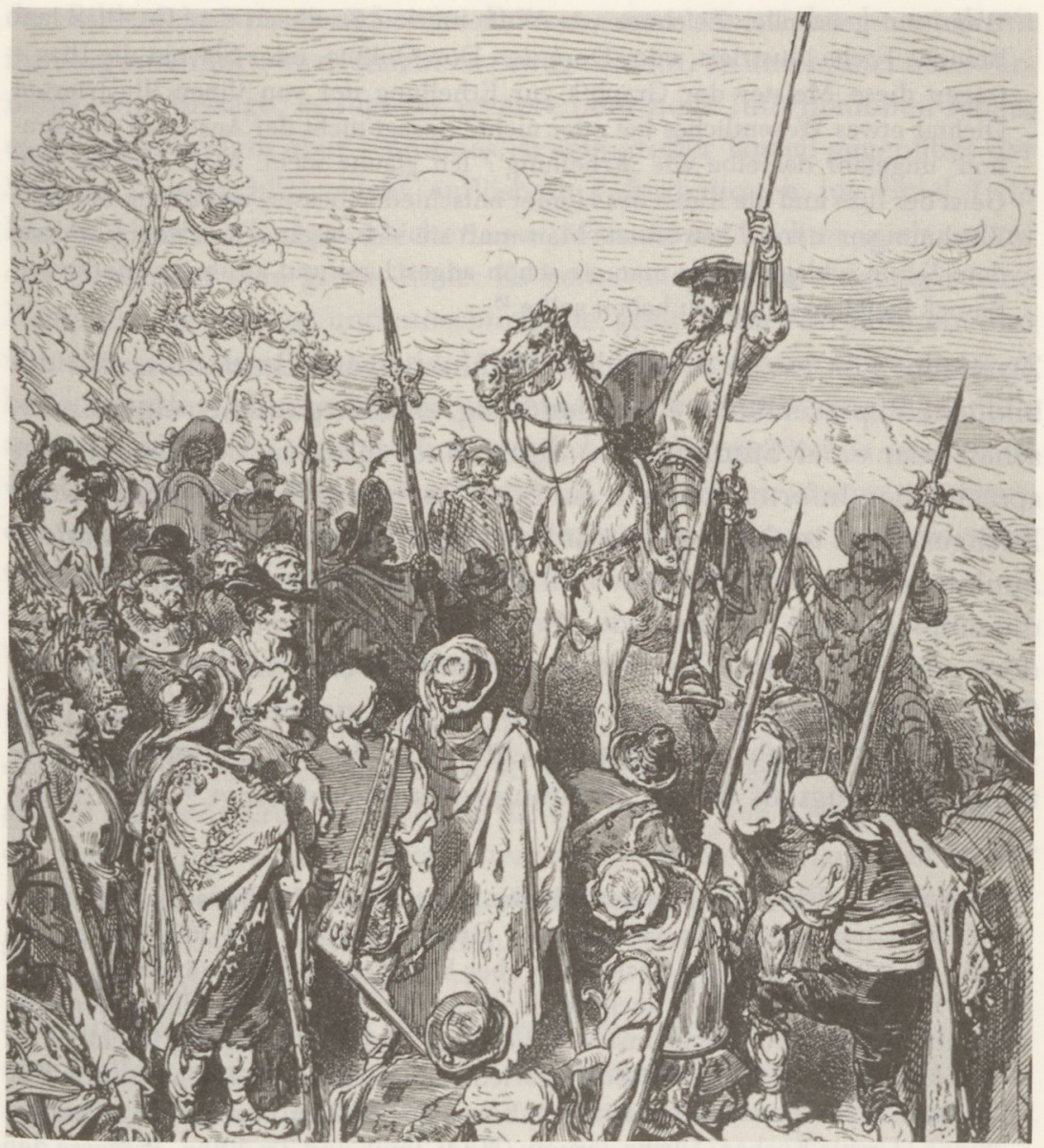

Abb. 7 Gustave Doré, Illustration zu ,Don Quijote de la Mancha‘, 1863

\section{Wort und Bild}

In der Buchgestaltung Lechters sind ungleich komplexere Bedeutungszuweisungen möglich. Doch welche Möglichkeiten der Korrelation von Wort und Bild sind überhaupt denkbar (Abb. 7), löst man sich einmal von dem Begriff der ,Illustration', der ja eigentlich nur Erhellung meint, und gegen den sich schon der Romanist Karl Vossler in dem Aufsatz ,Über gegenseitige Erhellung der Künste ${ }^{\natural}$ aus dem Jahr 1935 vehement gewandt hat: 
Wenn ein geistvoller Zeichner wie Wilhelm von Kaulbach den Goetheschen Reineke Fuchs illustriert, oder Doré den Don Quijote, oder Slevogt die Ilias tragen diese Meister der Graphik zur Erhellung der von ihnen illustrierten Dichter etwas Wesentliches bei oder nicht? Besagt nicht der Ausdruck ,Illustration' ungefähr dasselbe wie ,Erhellung'? Ich glaube nicht. Man versteht den Geist der Ilias und die Kunst des Homer entschieden besser, wenn man Slevogts Zeichnungen nicht betrachtet. Man muß sie sich sogar schon energisch aus dem Kopfe schlagen, falls man sie schon angeschaut und an ihrem modernen Barock Gefallen gefunden haben sollte. ${ }^{18}$

Zweifellos gibt es die illustrative Bildfunktion im Literalsinn, also die bildliche Repräsentation einer Handlung, eines Arguments, einer Landschaft oder einer Stimmung im Sinne einer direkten Übersetzung der sprachlichen Informationen in ein Bild. Doch darauf ist die Aufgabe des Buchgestalters in der Regel nicht beschränkt. Denn es gibt auch andere Funktionen der Bilder wie die affirmierende, die kontrafaktorische und die emblematisch-verrätselnde, die gerade nicht identifikatorisch, sondern enigmatisch ist. Das Bild ist bekanntlich eine andere Ausdrucksform, die nicht einfach Worte in visuelle Informationen übersetzt oder Realien repräsentiert, sondern dem literarischen Sinn andere Informationen hinzufügt als sie die Dichtung selbst hervorbringt. ${ }^{19}$ Auch muss

${ }^{18}$ Karl Vossler: Über gegenseitige Erhellung der Künste. In: Festschrift Heinrich Wölfflin zum siebzigsten Geburtstage, Dresden 1935, S. 160-167, hier S. 160.

${ }^{19}$ Für die wissenschaftliche Diskussion über Bildallegorien sind jüngere Ansätze der Frühneuzeitforschung auch für die Kunst um 1900, allemal für eine derart traditionsverhaftete Buchkunst wie diejenige Melchior Lechters, fruchtbar zu machen, vgl. Klaus Krüger: Bildallegorien in der italienischen Renaissance. Zur Hermeneutik visueller Topoi in der Kunst der Frühen Neuzeit. In: Thomas Frank/Ursula Kocher/Ulrike Tarnow (Hg.): Topik und Tradition. Prozesse der Neuordnung von Wissensüberlieferungen des 13. bis 17. Jahrhunderts, Göttingen 2007 (Berliner Mittelalter- und Frühneuzeitforschung 1), S. 193-207. Zur Begriffsklärung des Allegorischen s. den Überblick bei Walter Blank/ Bernhard F. Scholz: [Art.] Allegorie. In: Reallexikon der deutschen Literaturwissenschaft. Bd. 1. Hg. von Klaus Weimar u. a., Berlin - New York 1997, S. 40-48; Anselm Haverkamp/Bettine Menke: [Art.] Allegorie. In: Ästhetische Grundbegriffe. Historisches Wörterbuch. Bd. 1. Hg. von Karlheinz Barck, Stuttgart - Weimar 2000, S. 49-104. Zur älteren Diskussion vgl. Text und Bild. Bild und Text. DFGSymposion 1988. Hg. von Wolfgang Harms, Stuttgart 1990 (Germanistische Symposien. Berichtsbände 11); Gottfried Willems: Anschaulichkeit. Zu Theorie und Geschichte der Wort-Bild-Beziehungen und des literarischen Darstellungsstils, Tübingen 1989 (Studien zur deutschen Literatur 103); Dieter Sulzer: Traktate zur Emblematik. Studien zu einer Geschichte der Emblemtheorien. 
das Bild nicht immer auf einen Prätext verweisen, vielmehr wird mit ihm argumentiert; auch macht es etwas evident, es unterstützt oder verneint eine Aussage, es fügt ihr weitere oder neue Informationen hinzu, es bringt vor allem aber - und das ist sein großer Vorteil gegenüber der Sprache - sprachlich nicht auflösbare Informationen ins Spiel (wie Linien, Umrisse, Farben, Flächen usw.). Gerade bei Lechter spielt zudem das Ornament eine große Rolle. Es bettet allegorische oder figürliche Bilder ein, es umfängt und umschlingt sie, greift in ihre Struktur ein und überschneidet den Rahmen der bildlichen Fiktion, womit es keineswegs bedeutungsloser Buchschmuck ist. Diese spezifischen Bedingungen, unter denen Bildsinn entsteht und möglicherweise vorsätzlich produziert wird, sind zu bedenken, wenn man sich mit Bildern auseinandersetzt, die zu einer derart voraussetzungsreichen und komplexen Lyrik wie den Gedichten Stefan Georges geschaffen worden sind.

\section{Bilder zur Deutschen Dichtung}

Beispielhaft sei das analytische Verfahren nur an einem Werkkomplex durchgeführt, nämlich an der wohl wichtigsten Folge von Dichterallegorien aus dem Kreis der, Blätter für die Kunst', den Titelgestaltungen der von George und Wolfskehl herausgegebenen dreibändigen Reihe ,Deutsche Dichtung..${ }^{20}$ Die programmatische, gegen die bildungsbürgerlich-historistische Kanonbildung durch Stoffanhäufung in Gesamtausgaben und sentimentalen Blütenlesen gerichtete Auswahl - hier spielt der ästhetische Akt der Auswahl, die wiederum Urteil verlangt, eine Rolle - wird ikonographisch und ornamental durch Lechters Buchschmuck vereinheitlicht. Aus der Korrespondenz wissen wir, dass Lechter im Falle der ,Deutschen Dichtung' weitgehende Freiheit bei der Gestaltung hatte. Als George ihn drängte, ihm die Entwürfe zu zeigen,

Hg. von Gerhard Sauder, St. Ingbert 1992 (Saarbrücker Beiträge zur Literaturwissenschaft 22); Christel Meier: Überlegungen zum gegenwärtigen Stand der Allegorie-Forschung. Mit besonderer Berücksichtigung der Mischformen. In: Frühmittelalterliche Studien 10, 1976, S. 1-69.

${ }^{20}$ Deutsche Dichtung. Hg. von Stefan George und Karl Wolfskehl, Berlin 1900-1902; Zu Struktur und literaturgeschichtlichem Kontext der Anthologie s. Gerhard R. Kaiser: Anthologie: Kanon und Kanonskepsis. Hofmannsthal, George/Wolfskehl, Borchardt. In: Gerhard R. Kaiser/Stefan Matuschek (Hg.): Begründungen und Funktionen des Kanons. Beiträge aus der Literatur- und Kunstwissenschaft, Philosophie und Theologie, Heidelberg 2001, S. 107-138. 
wehrte Lechter ab, da er ihn mit dem fertigen Resultat überraschen wollte. Die allgemeinen ideen- und publikationsgeschichtlichen Hintergründe, welche den Entschluss zu einer Anthologie deutscher Dichtung bestimmt haben, müssen hier ausgeblendet werden; Gerhard R. Kaiser hat die Anthologie vor dem Hintergrund der Kanon-Debatte um 1900 erhellend dargestellt. An dieser Stelle soll sich jedoch allein auf die Analyse der Bilder beschränkt werden. Durch die Verwendung der StefanGeorge-Schrift für den Druck und auch durch die Buchgestaltung mit ähnlichen Titelbildern und Ornamenten wurde die Anthologie vereinheitlicht. Jedes aufgenommene Gedicht wurde dadurch zum Teil eines Ganzen, das die Einheit der deutschen Dichtersprache seit der klassischromantischen Kunstperiode bis zu Stefan George bezeugt. Möglicherweise ist die Dreizahl der Auswahlbände bereits bedeutend, wichtig ist aber die Polarität der beiden monographischen Anthologien von, Goethe " und ,Jean Paul' (also gleichsam von Lyrik und Prosa), die mit dem zuletzt erschienenen Band ,Das Jahrhundert Goethes' wiederum von einer diachronen Achse von Klopstock bis zu Mörike und Conrad Ferdinand Meyer durchschnitten wird, welche die Vor- und Nachgeschichte der Goethezeit enthält. Goethe wird hier zweifellos als das zentrale Ausstrahlungsphänomen begriffen, das sein Jahrhundert beherrscht hat:

DER NAME GOETHE BEHERRSCHT EIN GANZES DICHTERISCHES JAHRHUNDERT WENN AUCH NICHT SO ALS OB ALLES VOR IHM NUR VORBEREITUNG ALLES NACH IHM NUR AUSKLANG WÄRE DOCH KEINESWEGS DARF MAN IHM DER ALS GEGENSATZ ALLEIN JEAN PAUL VERTRÄGT EINEN ANDEREN BEIREIHEN - AM WENIGSTEN WIE MAN LEIDER NOCH IMMER THUT SCHILLER ODER HEINE: JENER DER FEINSTE SCHÖNHEITSLEHRER DIESER DER ERSTE TAGESSCHREIBER BEIDE ABER IN DIESEM ZWÖLFGESTIRN EHER DIE KLEINSTEN ALS DIE GRÖSSTEN UNSERE WAHL HAT NUR DIE VERFASSER GETROFFEN DEREN TON IHNEN SO EIGNET DASS ER KEINES ANDREN SEIN KÖNNTE NICHT SOLCHE DENEN EINMAL EIN GUTES LIED ODER EINE GUTE REIHE GELANG ES WIRD OFFENBAR DASS DER GARTEN DER DEUTSCHEN VERSKUNST NACH DIESER LICHTUNG SICH NICHT ÄRMER SONDERN IN UMSO DEUTLICHERER PRACHT ERWEIST. ${ }^{21}$

${ }^{21}$ George/Wolfskehl (Hg.), Deutsche Dichtung (Anm. 20), Bd. 3: Das Jahrhundert Goethes, S. 4-5 (Einleitung). 
Der erste Band der Anthologie, der im Jahr 1900 erschien, war ,Jean Paul. Ein Stundenbuch für seine Verehrer'. Hier zeigt die Titelillustration (Abb. 8) eine Harfe auf einem Blumenhügel, ein eher profanes Motiv also, das wenig an die sakrale Ikonographie des ,Teppichs des Lebens“ erinnert. Lechter hatte das Motiv der Harfe für die Ikonographie des ,Teppichs des Lebens ${ }^{6}$ ja bereits entdeckt und ausgebeutet. So erscheint die Harfe besonders bedeutsam am Ende des ,Teppichs'. Sinnfällig ist eine Saite gerissen, das Ende des Buches und das Verstummen des lyrischen Dichters bedeutend. Die Musik ist verklungen, die Öllampen geben kein Licht mehr, nur noch der letzte dünne Rauch kräuselt sich empor. Vier Großbuchstaben, auch sie zersprungen in zwei Teile, machen das „EN DE“ augenfällig. Auch im Falle der Jean Paul-Anthologie ist die Wirkung hochgespannt und feierlich, jedoch nicht sakral. Der zwischen den Bäumen durchscheinende Sternenhimmel verweist vermutlich auf den visionären Charakter der Dichtung Jean Pauls, auf den Hang der Romantik zur Nacht o. ä., aber nicht auf einen christlichen Gehalt. Die domestizierte Natur von Bäumen und Blumenkübeln, welche die Harfe als res significans des Bildes umgibt, ist symmetrisch organisiert. Das Bild gibt damit eine strenge Ordnung vor und sein Verständnis bereitet wenige Probleme. Ja, die Harfe auf dem Hügel, das Instrument des Dichters in der Natur, ist eine allgemein verständliche Dichtungsallegorie, die hier mit sepulkraler Bedeutung - nämlich einem Grabtumulus - verbunden wird. Kunstgeschichtlich ist dieses Bildkonzept ein Produkt der Romantik. Man erinnere sich nur an das im Geist der Freiheitskriege entstandene Grabmonument für Theodor Körner im mecklenburgischen Wöbbelin, das im September 1814 errichtet wurde. Körners Erfolgsbuch ,Leyer und Schwert‘ (Berlin 1814) gab die programmatische Vorgabe für die ikonographische Gestaltung des im Eisengussverfahren ausgeführten Denkmals, das auf einem klassizistischen Sockel eine von einem Schwert gekreuzte Leier zeigt und Körner als Repräsentanten vaterländischer Lyrik verewigt. ${ }^{22}$ Oder man denke an Carl Gustav Carus' Gemälde eines nicht realisierten Monuments „zu

${ }^{22} \mathrm{Vgl}$. dazu die Abbildungen in Hartmut Brun: Theodor Körner und der Krieg an der Niederelbe, Wöbbelin, Mahn- und Gedenkstätten Wöbbelin - TheodorKörner-Gedenkstätte, Wismar 1991; zum literatur- und ideengeschichtlichen Kontext s. Erhard Jöst: Der Heldentod des Dichters Theodor Körner. Der Einfluß eines Mythos auf die Rezeption seiner Lyrik und ihre literarische Kritik. In: Orbis litterarum 32, 1977, S. 310-340. 


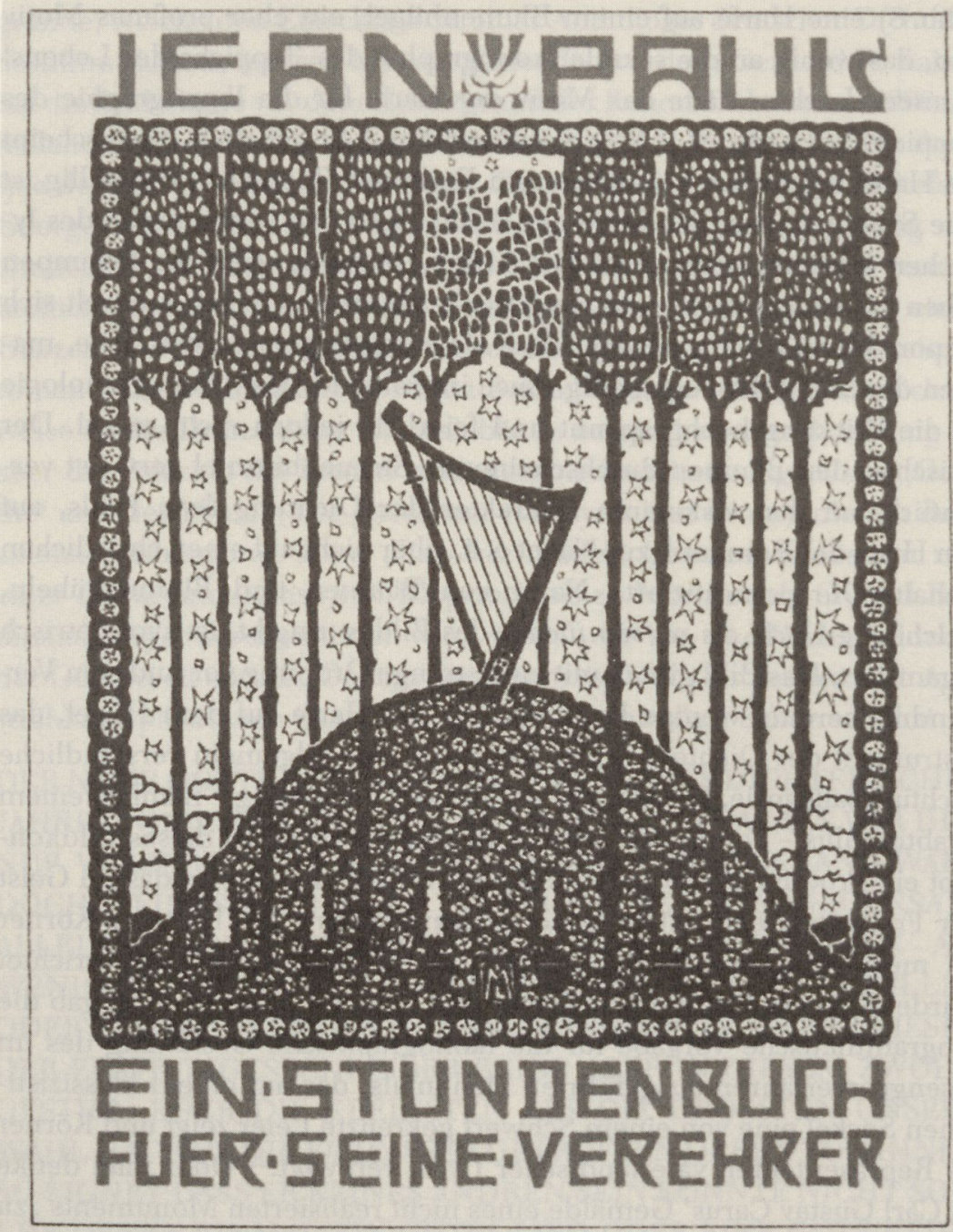

Abb. 8 Melchior Lechter, Titelbild zu ,Jean Paul`, 1900 
Goethes Ehrengedächtnis“ aus dem Jahre 1832 (Abb. 9). ${ }^{23}$ Hier ist die Ikonographie ungleich komplexer, bringt das Bild doch Natur und Kunst wirkungsvoll zusammen. Genau genommen funktioniert das von Carus imaginierte Monument auch nur in und mit der umgebenden Natur. Auf einem in gotischen Formen gestalteten Sarkophag, dessen Inschrift ihn als Goethes Sarkophag ausweist, ist die Harfe aufgestellt, zu deren Seiten andächtig zwei Engel knien. Mondlicht streift durch die Saiten und Gewölk lagert sich um die Bergspitzen, während das Tal von Nebel erfüllt ist. Vielfältig sind hier die Anknüpfungsmöglichkeiten an Goethes Werk, wobei der kleinste gemeinsame Nenner die Überlegung sein mag, dass die Natur den Dichter Goethe stimuliert und diese die Werke erst hervorgebracht habe. Ja, Goethe habe gleich einer Äolsharfe, in die der Wind greift, unbewusst wie die Natur herrliche Töne produziert. Donat de Chapeaurouge hat in seiner Deutung des Gemäldes den Aspekt der Äolsharfe stark gemacht und auch daran erinnert, dass diese als ein Instrument begriffen wurde, mit dem Stimmen aus dem Jenseits hörbar gemacht werden konnten, wodurch das von Carus projektierte Denkmal in der Einöde erst einen tröstlichen Sinn für die Nachwelt mache. In Jean Pauls ,Titan', und hiermit kehren wir zum Gegenstand des ersten Bandes der Anthologie ,Deutsche Dichtung` zurück, findet sich die Beschreibung einer Äolsharfe am offenen Fenster:

Indem das Kind mit dem Fäustchen auf dem Klavier nachdonnerte und die Vögel aus den Bäumen freudig darein schrieen, so fuhr der Weltgeist durch die Äolsseiten jauchzend und seufzend, regellos und regelmäßig, spielend mit den Stürmen und sie mit ihm; und Albano hörte, wie die Ströme des Lebens laut rauschten zwischen den Ufern der Länder - und durch die Blumen und Eichenadern - und durch die Herzen - um die Erde, Wolken tragend - und den Strom, der durch die Ewigkeit donnert, goß ein Gott aus unter dem Schleier. ${ }^{24}$

${ }^{23}$ Das Gemälde in Hamburg, Kunsthalle, Inv. Nr. HK 1157. Vgl. Donat de Chapeaurouge: Carus' Gemälde, Zu Goethes Ehrengedächtnis‘von 1832. In: Zeitschrift für Kunstgeschichte 61, 1998, S. 113-117; Carl Gustav Carus. Natur und Idee. Ausstellungskatalog. Dresden, Staatliche Kunstsammlungen und Berlin, Staatliche Museen. Hg. von Petra Kuhlmann-Hodick/ Gerd Spitzer/Bernhard Maaz, Berlin - München 2009, Bd. 2: Katalog, S. 132, Kat. Nr. 116 (Bernhard Maaz).

${ }^{24}$ Jean Paul: Titan. In: Ders.: Werke in 6 Bänden. Hg. von Norbert Miller, Bd. 3: Titan, München 1961, S. 333-334 (Vierzehnte Jobelperiode). 


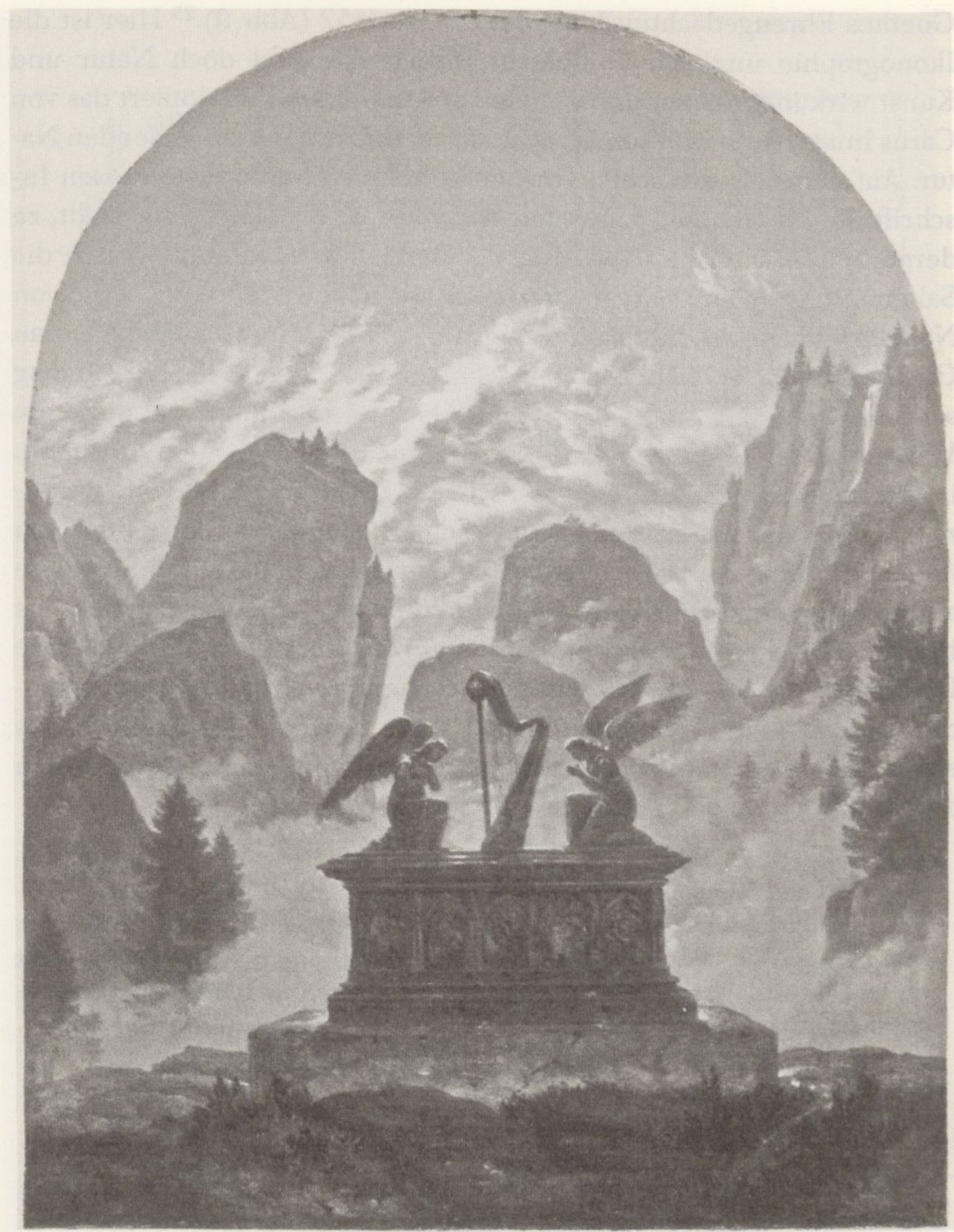

Abb. 9 Carl Gustav Carus, ,Zu Goethes Ehrengedächtnis‘', 1832, Hamburg, Kunsthalle 
Es würde zu weit führen, die Exegese des Gemäldes von Carus hier fortzuführen, zumal Lechters Kenntnis des Bildkonzepts nicht zu belegen ist, ja diese doch wohl eher unwahrscheinlich sein dürfte. Dennoch, Lechter griff hier auf ein wohlbekanntes romantisches Bildmotiv zurück, das in seinem neuen Verwendungszusammenhang für eine Jean PaulAnthologie auch einen neuen Sinn produzierte. Doch welchen? Die Harfe, die strenge Stilisierung des sie umgebenden Heiligen Hains wie auch die Bezeichnung als ,Stundenbuch“ widersprechen gewissermaßen dem Inhalt des Buches, nämlich Ausschnitte von Prosatexten aus Jean Pauls Romanen wiederzugeben. Jean Paul war ja im 19. Jahrhundert ein durchaus vielgelesener Autor, dessen geistreiche Sprache und skurrilen Einfälle viele Liebhaber fanden. Sein Werk wurde vor allem mit Witz verbunden. ${ }^{25}$ Das Titelbild verkündet jedoch programmatisch, dass man es hier mit Dichtung zu tun hat, was ja auch den Kriterien Georges und Wolfkehls bei der Auswahl entsprach, nämlich die Stellen von dichterischem Gehalt zu isolieren und damit einen ganz anderen Autor, nämlich den Dichter Jean Paul hervortreten zu lassen. Auch der Akzent der Auswahl auf der Wiedergabe von Träumen aus Jean Pauls Romanen und Erzählungen ist dieser Umwertung der genuin poetischen Qualitäten ihres Verfassers geschuldet. Hier lässt sich das Verhältnis von Bild und Buch als komplementär bezeichnen, das Bild behauptet einen Anspruch, der auch den Intentionen der Herausgeber entsprach. Die Bezeichnung als "Stundenbuch" für Verehrer eröffnet wiederum einen sakralen, wenn nicht sogar kunstreligiösen Bezugsrahmen. Die Behauptung, dass man es hier überhaupt mit hochrangiger Dichtung, ja Texten für eine gefühlvolle, quasi andächtige Versenkung, zu der ja ein Stundenbuch in der religiösen Praxis dient, zu tun haben könnte, wird den Texten von Bild und Titel aufgeladen.

Bei dem im Spätherbst 1901 erschienenen,Goethe ${ }^{6}$ ist der Fall etwas anders gelagert. Die Auswahl aus Goethes Werk wird von einem Bild eröffnet (Abb. 10), das als affirmativ zu bezeichnen ist, da es der alten, schon zu Lebzeiten des Dichters entstandenen Vorstellung von dem ,Olympier' Rechnung trägt. Eingerahmt von Lorbeer, dem traditionellen Dichterattribut, fällt der Blick auf ein Bildfeld, in dessen Zentrum,

${ }^{25}$ Vgl. Jean Paul im Urteil seiner Kritiker. Dokumente zur Wirkungsgeschichte Jean Pauls in Deutschland. Hg. von Peter Sprengel, München 1980 (Wirkung der Literatur 6). 


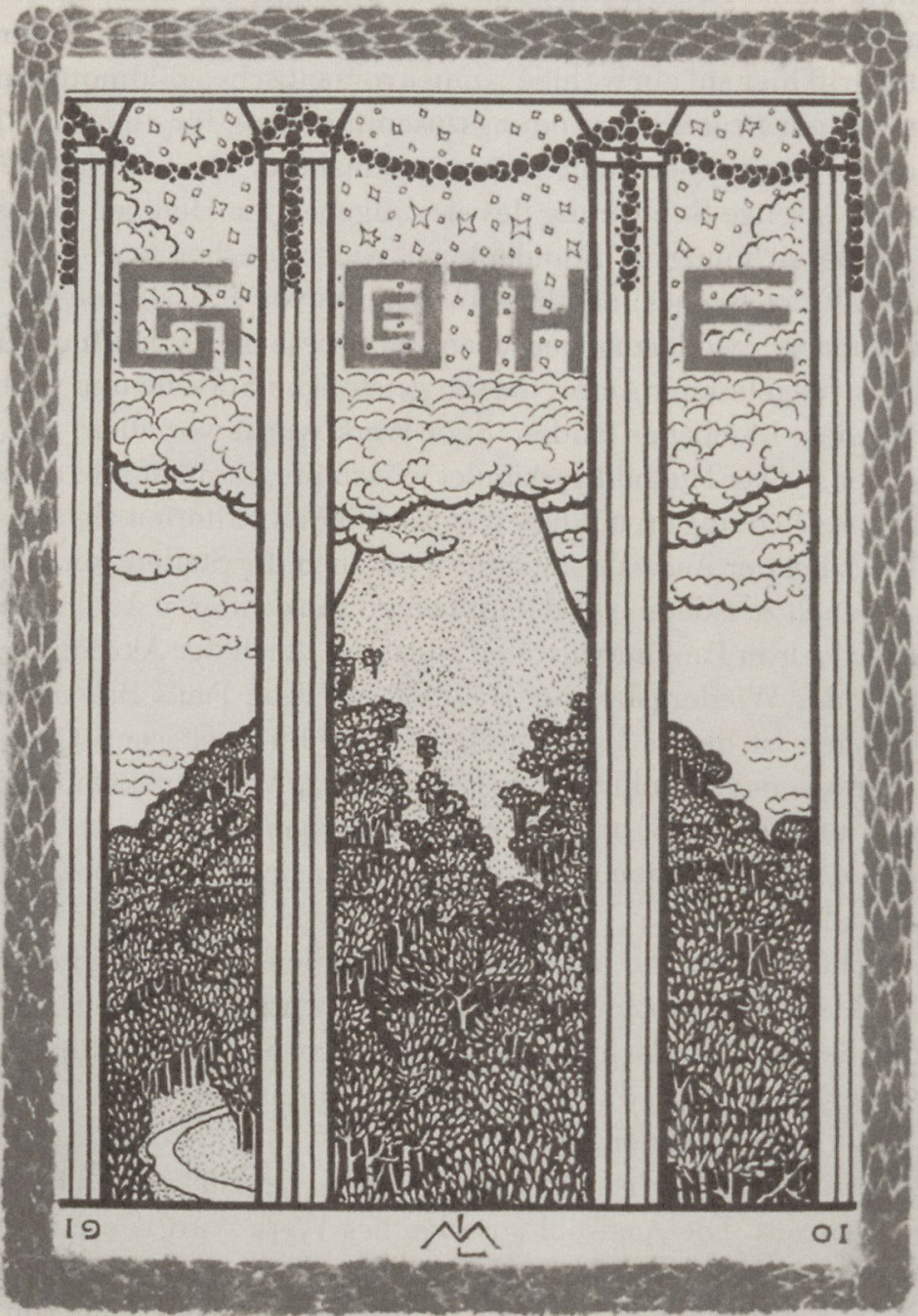

Abb. 10 Melchior Lechter, Titelbild zu ,Goethe', 1901 
hinter einer Säulenstellung verborgen, ein steiler Berg aufragt, zu dem ein Weg führt und dessen Gipfel in den Wolken verborgen ist. Darüber breitet sich das von Sternen bedeckte Firmament aus. Der Berg erscheint hier in seiner ins Numinose reichenden Höhenerstreckung als ein Ort der Begegnung von Himmel und Erde, mehr noch: als geheimnisvoll verhüllter Ort des Austauschs von Göttlichem und Irdischem. Nur dem Künstler - Goethes Name prangt in rot gedruckten Versalien auf dem Firmament - scheint dieser Ort zugänglich. Keine anthropomorphe Allegorie, kein Portrait, sondern die Metapher, es bei Goethe mit dem ,Gipfel ${ }^{6}$ der deutschen Dichtung zu tun zu haben, dürfte die Bildfindung geleitet haben, die sich allerdings auch auf einen prominenten Prätext bezieht. Georges und Wolfskehls Goethe-Auswahl wird nämlich von der 1784 geschriebenen und 1787 erstmals der GöschenAusgabe der ,Schriften ' vorangesetzten ,Zueignung' eröffnet. ${ }^{26}$ Goethe wollte dieses Programmgedicht eigentlich seinem auf die Darstellung und Klärung grundlegender Menschheitsfragen ausgerichteten Epos ,Die Geheimnisse‘ voranstellen. ${ }^{27}$ Da das Epos Fragment blieb, verwendete Goethe das Gedicht in anderen Zusammenhängen, so dass es, als es 1787 dem ersten Band der, Schriften' vorangestellt wurde, auch als Bekenntnisgedicht zum Wesen der Dichtung allgemein verstanden werden konnte. Diese allgemeine Bedeutung, die mit der auffällig allegorischen Bildsprache des Gedichts korrespondiert, machte auch 1901 seine Verwendung als Eröffnungsgedicht im Kontext der Anthologie ,Deutsche Dichtung، möglich. Denn in dem Gedicht geht es um das Wesen der Dichtung im Allgemeinen wie auch im Besonderen, auf die Autor-

${ }^{26}$ George/Wolfskehl (Hg.), Deutsche Dichtung, Bd. 2: Goethe (Anm. 20), S. 6-9. 27 Johann Wolfgang Goethe: Zueignung. In: Ders.: Sämtliche Werke nach Epochen seines Schaffens (Münchner Ausgabe). Hg. von Hartmut Reinhardt, Bd. 2.1: Erstes Weimarer Jahrzehnt 1775-1786, München 1987, S. 93-96; zur Entstehung vgl. den Kommentar ebd., S. 599-601. Grundlegend zur Interpretation noch immer Oskar Walzel: „Der Dichtung Schleier aus der Hand der Wahrheit". In: Euphorion 33, 1932, S. 83-105; Rainer Nägele: Das Imaginäre und das Symbolische. Von der Anakreontik zum Schleiersymbol. In: Gerhart Hoffmeister (Hg.): Goethezeit. Studien zur Erkenntnis und Rezeption Goethes und seiner Zeitgenossen, Bern - München 1981, S. 45-63; Daniel Fulda: „Der Wahrheit Schleier aus der Hand der Dichtung“. Textilmetaphern als Vehikel und Reflexionsmedium ästhetisch-wissenschaftlicher Transferenzen um 1800. In: Johannes Endres / Barbara Wittmann / Gerhard Wolf (Hg.): Ikonologie des Zwischenraums. Der Schleier als Medium und Metapher, München 2005, S. 165-186. 
persönlichkeit Goethes bezogenen Sinne. Das Gedicht, an dessen Kulminationspunkt das lyrische Ich den aus Wolken und Duft geknüpften und in "tausend Falten" fließenden "Dichtung Schleier aus der Hand der Wahrheit" (Vers 96) empfängt, beginnt mit der Schilderung des morgendlichen Aufstiegs auf einen Berg, auf den sich der Dichter begibt, um mit einer schönen Frauengestalt Zwiesprache zu halten, deren Bedeutung zwischen Muse der Dichtkunst und Göttin der Wahrheit oszilliert, und in die möglicherweise auch - wie ältere biographische Interpretationen stärker akzentuiert haben - das Bild der Charlotte von Stein eingeschrieben ist. Es ist evident, dass Lechter dieses symbolträchtige und grandiose Naturerlebnis, das Goethe - alten Vorstellungen vom Tugendberg folgend - in das Bild des Aufstiegs gefasst hat, zu seinem Titelbild inspiriert hat. Denn dort umhüllen zunächst Nebel, dann Wolken den aufsteigenden Dichter und verbieten den Blick in das Tal hinab - Lechter zeigt entsprechend einen steilen Berg mit von Wolken verhülltem Gipfel. Im Gedicht gelangt der Dichter in eine Zone der Dämmerung, durch die plötzlich Sonnenlicht von hellster Klarheit auf ihn fällt - eine Erfahrung des Numinosen, der Lechter offenbar mit seinem stilisierten Sternenhimmel bildliche Form verleihen wollte:

Und wie ich stieg, zog von dem Fluß der Wiesen

Ein Nebel sich in Streifen sacht hervor.

Er wich und wechselte mich zu umfließen

Und wuchs geflügelt mir ums Haupt empor:

Des schönen Blicks sollt' ich nicht mehr genießen,

Die Gegend deckte mir ein trüber Flor;

Bald sah' ich mich von Wolken wie umgossen,

Und mit mir selbst in Dämmerung eingeschlossen.

Auf einmal schien die Sonne durchzudringen,

Im Nebel ließ sich eine Klarheit sehn.

Hier sank er leise sich hinabzuschwingen;

Hier teilt' er steigend sich um Wald und Höhn.

Wie hofft' ich ihr den ersten Gruß zu bringen!

Sie hofft' ich nach der Trübe doppelt schön.

Der luft'ge Kampf war lange nicht vollendet,

Ein Glanz umgab mich und ich stand geblendet. ${ }^{28}$

Auf dem Gipfel gelangt der Dichter an den Ort der Erkenntnis, da er einem „göttlich Weib“ (Vers 30) begegnet, das Muse der Dichtung und

${ }^{28}$ Goethe, Zueignung (Anm. 27), S. 94, Vers 9-24. 
Allegorie der Wahrheit zugleich ist. Die Wechselrede von lyrischem Ich und allegorischer Figur weitet die Thematik der ,Zueignung“ auf das zentrale Thema von Dichtung und Wahrheit aus. Diese, die Wahrheit, sei nämlich nur durch den verhüllenden und zugleich sichtbar machenden Schleier der Poesie den Menschen zugänglich und zumutbar. Aber der Text von Goethes Programmgedicht, das als ein poetologisches Bekenntnis zu verstehen ist, ist nur ein, wenn auch wesentlicher Ausgangspunkt für Lechters Bilderfindung. Erst jetzt setzt nämlich das Spiel mit den verschiedenen Bedeutungen ein, die sich aus der Tatsache ergeben, dass das Bild einer Goethe-Anthologie voransteht und dem Bild der Name eben dieses Dichters buchstäblich eingeschrieben ist. Das poetische Naturbild der ,Zueignung' wandelt sich von einer umfassenden Allegorie dessen, was die Dichtung vermag, nämlich „Wahrheit" durch den Schleier der Poesie überhaupt erst anschaulich und fassbar werden zu lassen, zu einer speziellen Dichterallegorie, die ganz individuell auf den größten neuzeitlichen Dichter in deutscher Sprache, auf Goethe selbst, ausgerichtet ist. Die Einzelbestandteile von Lechters Bildallegorie sind mit Bedacht gewählt und gehen auch insofern über eine Illustration der ,Zueignung ' hinaus, als sie die beiden für Goethes Werk entscheidenden Pole Natur und Antike ins Bild setzen. Die stilisierte dorische Säulenstellung schiebt sich nämlich gleichsam vor das Bild der Natur. Ornamental verbunden werden die Säulen durch eine Girlande hier handelt es sich um Festons, wie sie die antiken Tempel geschmückt haben sollen, die im bildlichen Kontext des Goethe-Lobs an das spielerische Band der Poesie erinnern mögen. Diese Bildallegorie, die das Bild von Tempel und erhabener Natur an die Stelle des Autorportraits setzt, greift zu guter Letzt in ihrem auf die Apotheose des Dichters ausgerichteten Anspruch bereits gereifte Topoi der Goethe-Verehrung auf, nämlich in dem Dichter den Höhepunkt der deutschen Dichtung, eben den ,Olympier' (und dabei schwingt die Antike zweifellos mit) zu sehen. Goethe hatte dieser Nobilitierung durch seine Mitwelt bekanntlich bereits zugearbeitet, in dem er sein Leben selbst zum Kunstwerk stilisiert hat.

Das abschließend im Oktober 1902 erschienene ,Jahrhundert Goethes' fasst das von Goethe geprägte Jahrhundert zusammen. Die Auswahl der Gedichte spiegelt vornehmlich den Einfluss, den Goethe und die Klassik auf die deutsche Dichtersprache ausgeübt haben. Die Bildallegorie des Titels (Abb. 11) verweist hierbei aber nicht auf einen his- 


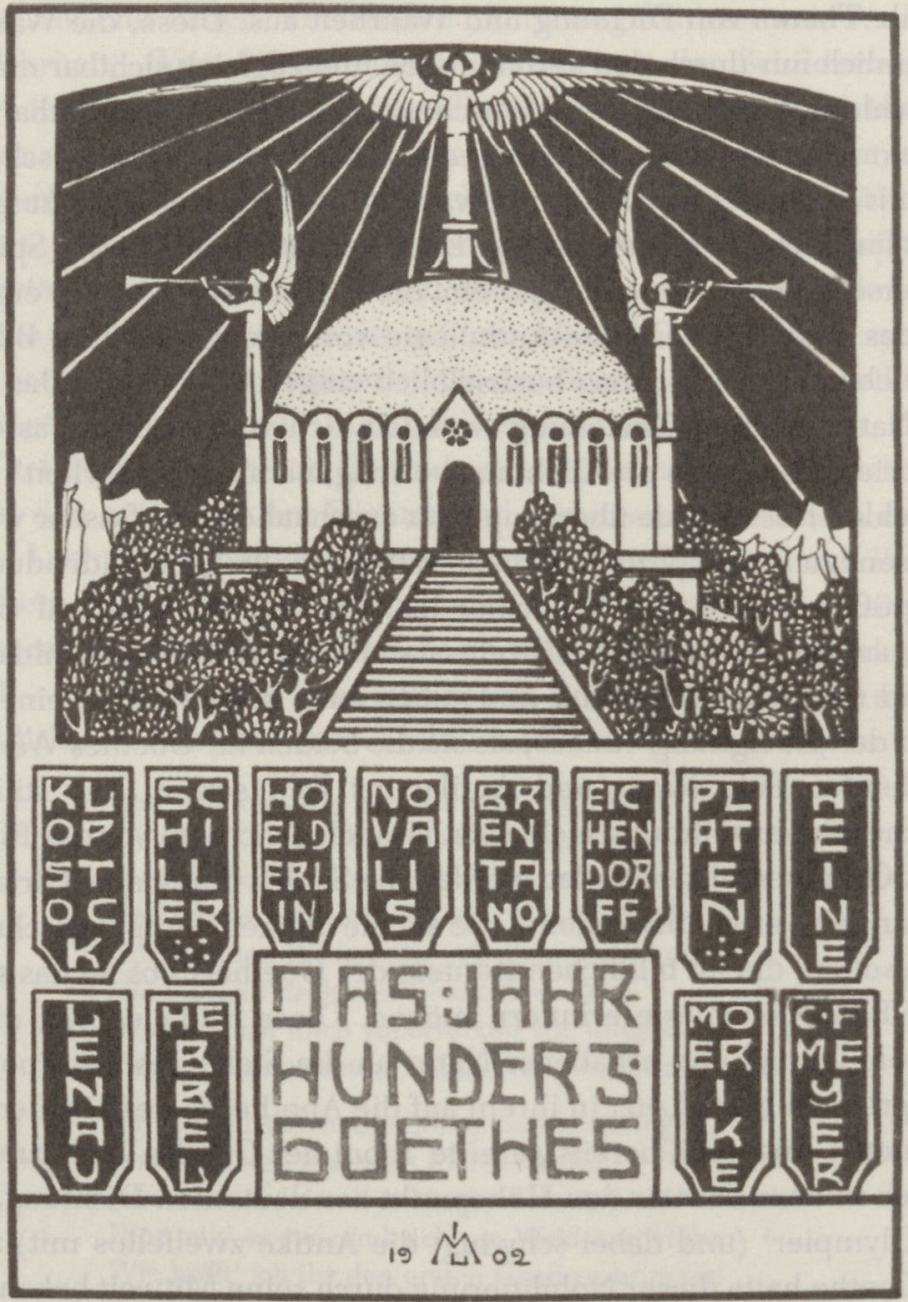

Abb. 11 Melchior Lechter, Titelbild zu ,Das Jahrhundert Goethes‘, 1902 
torischen Prozess der Aneignung mit gewissermaßen offenem Ausgang. Vielmehr macht das Titelbild eine klare Ansage. Es handelt es sich um eine zwischen Wald und Hochgebirge gelegene Ehrenhalle, ein gotisches (hier wohl immer noch als deutscher Baustil verstanden) Pantheon, in dem die Erinnerung an die Dichter unter stilisierten posaunenblasenden Ruhmesgenien aufgehoben ist. Eine steile Treppe führt zu dieser Ruhmeshalle, die einerseits an die alte Vorstellung vom Tugendweg und Tugendtempel, in der kunsthistorischen Realität andererseits an die von Leo von Klenze in der freien Natur oberhalb der Donau bei Regensburg erbaute Walhalla (Abb. 12), das ,Pantheon' der Deutschen, und vergleichbare Ehrenhallen des 19. Jahrhunderts erinnert. ${ }^{29}$ Dem überzeugten Wagnerianer Lechter dürfen aber auch Assoziationen an eine Gralsburg unterstellt werden, wie sie sich in der Illustration des späteren 19. Jahrhundert bildlich geformt hatten. ${ }^{30}$

Die Zwölfzahl der Auswahl lässt wohl nicht ungewollt sakrale Assoziationen zu, denn in dieser Perspektive erscheinen die zwölf ins Pantheon aufgenommenen Dichter wie die Apostel des einzigen Zentralgestirns Goethe. Damit ist der Ehrentempel der deutschen Dichtung zweierlei, nämlich säkulare Ruhmeshalle und ein quasi sakraler Ort des Heils, an dem das Andenken an die Kunst, deren Verehrung ja nur kunstreligiös zu denken ist, gestiftet wird. Ohne Frage ist dieses Bild, gerade im Zusammenspiel mit den inschriftlich niedergelegten Dichternamen, eine Kanonbehauptung, die in ihrer kompromisslosen Stilisierung jeglichen Einspruch schwer macht. Und bei der Formulierung dieses Kanons kommt es ebenso auf die Namen an, die genannt sind, wie auf diejenigen, die fortgelassen werden.

${ }^{29} \mathrm{Vgl}$. Reinhold Baumstark: Walhalla. Der Tempel für die deutsche Kulturnation. In: Alois Schmid/Katharina Weigand (Hg.): Schauplätze der Geschichte in Bayern, München 2003, S. 309-329; Walhalla. Ruhmestempel an der Donau. Ein Bildband. Hg. von Horst Hanske/Jörg Traeger, Regensburg ${ }^{4} 2002$; Die Walhalla. Idee, Architektur, Landschaft. Hg. von Jörg Traeger, Regensburg 1979. Zum ideengeschichtlichen Kontext des ,Kults der großen Männer', dem ja auch Lechters Bildallegorie verpflichtet ist, vgl. Le culte des grands hommes du Panthéon au Walhalla. Hg. von Thomas W. Gaehtgens / Gregor Wedekind, Paris 2009 (Passagen 16).

30 Über diese historischen Referenzen hinaus fühlt man sich im zeitlichen Kontext der Jahrhundertwende aber auch an Gebrauchsarchitektur wie Krematorien, Bahnhofs- und Lokhallen sowie an die Architektur der Jahrhunderthallen erinnert. 


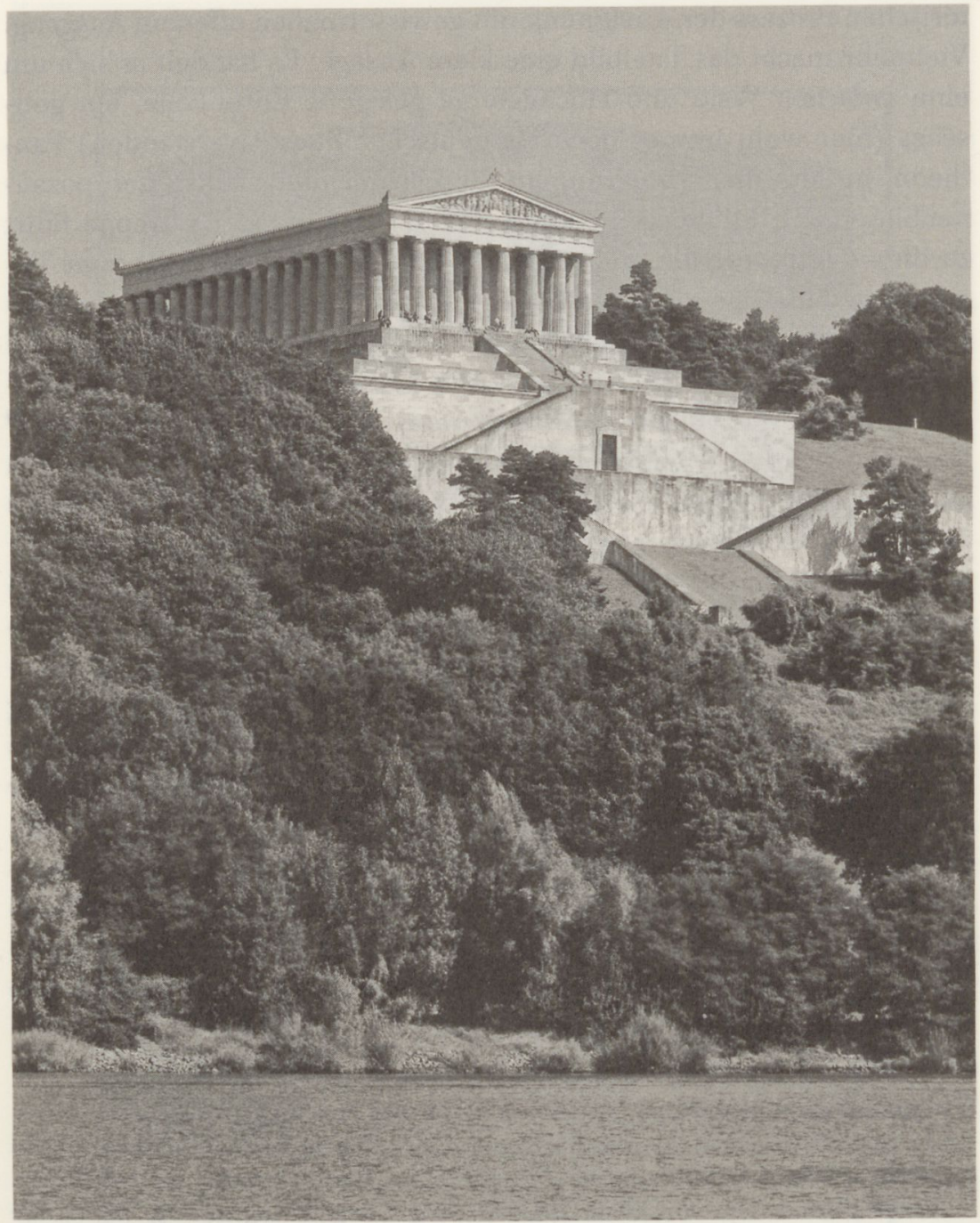

Abb. 12 Leo von Klenze, ,Walhalla', 1830-1842, Regensburg 
Um zu einem vorläufigen Resümee zu gelangen: Bilder und Buchschmuck der Publikationen Stefan Georges bis 1907 sind sicher nicht als ein Missgriff des Dichters zu bezeichnen, der seine Werke in die Hände eines inadäquaten Buchkünstlers legte, der über ihren autonomen Status und lyrischen Gehalt hinweg einen Teppich von Ornament ausgebreitet hat, unter dem die eigentliche Dichtung begraben wurde. Vielmehr lassen sich die ikonographischen Motive und allegorischen Gestaltungen der Bücher šehr wohl der Gedankenwelt Georges zurechnen, ja dürften in weitgehendem Einverständnis mit dem Dichter entwickelt worden sein. Die Bilder konnten dabei programmatischen Gedanken und ästhetischen Setzungen Evidenz verleihen. Ob man dies nun als ästhetisch überzeugend, geglückt, oder absolut verunglückt bezeichnen mag, bleibe dahingestellt und berührt den Bereich des Geschmacksurteils, der nicht Thema dieses Beitrags ist. In jedem Fall greifen Beschreibungen zu kurz, welche in den Bildern lediglich Illustrationen, also mehr oder weniger verzichtbare Zutaten zu einer im zeit- und geschichtslosen Raum schwebenden Dichtung erkennen. 